\title{
MARIÁtegui y Benjamin, EL ITINERARIO DEL INTELECTUAL VANGUARDISTA
}

Jaime Villarreal

(Benemérita Universidad Autónoma de Puebla)

Pero la ficción no es libre. Más que descubrirnos lo maravilloso, parece destinada a revelarnos lo real. La fantasía, cuando no nos acerca a la realidad, nos sirve bien poco. Los filósofos se valen de conceptos falsos para arribar a la verdad. Los literatos usan la ficción con el mismo objeto. La fantasía no tiene valor sino cuando crea algo real. Ésta es su limitación. Éste es su drama. José Carlos Mariátegui ("La realidad y la ficción")

En este artículo exploro temas, problemas y procedimientos concurrentes en la ensayística de dos pensadores trascendentales de la primera mitad del siglo XX en sus respectivos contextos, el peruano José Carlos Mariátegui (1894-1930) y el alemán Walter Benjamin (1892-1940). Me interesa destacar la compatibilidad y la posteridad de su pensamiento político, literario y estético como clave de lectura de un perfil intelectual surgido al calor de la Gran Guerra, la Revolución rusa y las vanguardias históricas, el del intelectual vanguardista, cuyos recursos más depurados enarboló y heredó para el mundo hispánico el Amauta. Adicionalmente, me interesa aportar algunos indicios del gran ascendiente que ha tenido para algunas escrituras ensayísticas iberoamericanas la obra de Walter Benjamin. 


\section{Grandes diferencias}

Si bien Walter Benjamin escribió en francés, sobre todo en su periodo de exilio parisino, desde1933 hasta su muerte en 1940, su lengua de producción fue el alemán, lo que anula prácticamente la posibilidad de que Mariátegui, asiduo lector de publicaciones francesas, fallecido en 1930 y quien no tuvo al alemán como una de sus lenguas de lectura, se haya encontrado con alguno de sus ensayos. Empecemos entonces por algunas de las grandes diferencias de estos autores que no Ilegaron a conocerse ni a leerse,

Por un lado, Benjamin, heredero de la gran tradición intelectual de Europa occidental, marcada por el idealismo, el romanticismo, el misticismo judío y el materialismo histórico, proveniente de una familia judía alemana liberal de clase acomodada, se formó en Filosofía en universidades de su país y de Suiza (Friburgo, Berlín y Berna) y presidió la Unión de Estudiantes Libres (Berlín) en su temporada como universitario. Aunque, eso sí, resultó tan heterodoxo que nunca pudo conseguir una posición en la academia alemana que, por igual, lo consideró muy filosófico para ser un letrólogo o muy literario para filósofo. Es conocido tanto el rechazo académico de su tesis de habilitación, El origen del drama barroco alemán (redactada en 1925), en la Universidad de Frankfurt, como la marginación de sus artículos en los círculos disciplinarios. Con frecuencia su trayectoria se esquematiza marcada por tres etapas: la juvenil teológica y estudiantil, caracterizada por su acercamiento a la cábala y la influencia de su amistad con Scholem; la romántica, que produjo su tesis doctoral de 1918: El concepto de crítica de arte en el romanticismo alemán; y la materialista, cuya obra mayor es Sobre el concepto de la historia (1940). Habría que matizar y aceptar que estos ingredientes están presentes en diferentes dosis y combinaciones en casi toda su obra.

Por otro lado, Mariátegui, nacido dentro de una familia católica de clase baja en Moquegua, en el sureste peruano, se crió con carencias materiales y de salud. Abandonado por su padre, Francisco Javier Mariátegui y Requejo, limeño de clase acomodada descendiente del prócer independentista Francisco Javier Mariátegui y Tellería; quedó en precariedad al cuidado de su madre costurera, María Amalia La Chira. Si bien su hermana Guillermina le había enseñado a leer y escribir incluso antes de iniciar la instrucción formal, una artritis tuberculosa lo obligó a abandonar la primaria luego de cursar el primer año, una caída le provocó la cojera que sufrió durante toda su vida. Así se hizo gran lector: autodidacta por necesidad, se declaró en algún momento antiuniversitario. Cuando tenía unos 16 años, definió un perfil de intelectual artista -en términos de Zanetti- formado en el periodismo y las 
bibliotecas, muy a la manera de los modernistas hispanoamericanos, como Martí, Darío, Gutiérrez Nájera o Nervo', portando un seudónimo, Juan Croniqueur (en correspondencia, Benjamin también tuvo sus alias). Convertido en activista y una voz periodística respetada y peligrosa en el Perú, fue enviado al exilio europeo por el gobierno de Leguía junto a su compañero de proyectos periodísticos, César Falcón. Así, el mismo Mariátegui consideró su período juvenil de 1911 a 1919, como su "edad de piedra"; su temporada en Europa, de 1919 a 1923, como sus "años de aprendizaje", y, por descarte, su última etapa, a pesar de su evidente juventud, desde su regreso a Perú hasta su muerte en 1930, su "edad madura". Encontró asideros latinoamericanos para su reflexión en el proceso revolucionario mexicano, en sus ideólogos y artistas, además de la Reforma Universitaria de Córdoba (1918), también de repercusiones continentales. No estudió la Revolución Mexicana con el ahínco de otros temas y problemas, aunque como otros progresistas de Latinoamérica observó con mucho interés el proceso por el cual por primera vez en un país hispanoamericano se fracturaba el sistema oligárquico semifeudal prevaleciente durante el siglo XIX².

\section{Grandes coincidencias: la crítica romántica de la modernidad}

Marxistas heterodoxos que desarrollaron una escritura fragmentaria, lectores de los filósofos franceses Henri Bergson (1859-1941) y Georges Sorel (1847-1922), Mariátegui y Benjamin han sido considerados representantes de un marxismo romántico muy atento a la reflexión literaria y estética.

\footnotetext{
La crítica romántica de la modernidad capitalista se hace en nombre de valores sociales, éticos, culturales o religiosos pre-capitalistas, y constituye, en último análisis, una tentativa desesperada de "re-encantamiento del mundo". Puede tomar formas regresivas y reaccionarias, pero también utópicas y revolucionarias, como por ejemplo en la corriente marxista que se podría definir como "romántica" -de William Morris a E. P. Thompson, del joven Lukács a Ernst Bloch, y de Walter Benjamin hasta Herbert Marcuse [Löwy 2005: 50].
}

Partidario de la revolución socialista, de hecho, el mismo Mariátegui habló en su trascendente ensayo "Dos concepciones de la vida" $(1925)^{3}$ sobre el romanticismo como una tendencia contemporánea manifiesta en proyectos de derecha y de izquierda.

\footnotetext{
${ }^{1}$ Remito aquí al gran estudio sobre la crónica modernista del estudioso puertorriqueño Julio Ramos, Desencuentros de la modernidad en América Latina (1989).

${ }^{2} \mathrm{Al}$ respecto puede consultarse el artículo "Mariátegui: México y su revolución" de Giovanni Casetta (Anuario Mariateguiano Vol. VI, No. 6, Lima, Amauta, 1994, pp. 104 - 124.

${ }^{3}$ Incluido en El alma matinal, publicado originalmente en Mundial (9 de enero de 1925).
} 
De esta manera, incitados por el acontecimiento más aterrador y fascinante de su época, la Gran Guerra, ambos definieron varias de las que de ahí en adelante serían disyuntivas fundamentales de la intelectualidad. La sustitución de la política por la estética en el futurismo italiano, la excesiva confianza en el yo de la filosofía de Bergson en tiempos de Proust y de Freud, la crítica al artista romántico purista que evade la condición de productor obligada por el capitalismo moderno, el interés en el surrealismo como vanguardia artística emancipatoria que conjugaba antirracionalismo y compromiso comunista, la crítica al progreso, en todo ello coinciden dos ensayistas que siguen siendo leídos como claves de interpretación de la actualidad.

Benjamin y Mariátegui coinciden no sólo en la crítica de la modernidad sino en la vocación moderna emancipatoria. Así lo establece Löwy acerca de Benjamin:

\footnotetext{
La concepción de la historia de Benjamin no es posmoderna, ante todo porque, lejos de estar "más allá de todos los relatos" -en el supuesto de que algo así sea posible--, constituye una forma heterodoxa del relato de emancipación: inspirada en fuentes mesiánicas y marxistas, utiliza la nostalgia del pasado como método revolucionario de la crítica del presente. Su pensamiento por tanto no es "moderno" (en el sentido habermasiano) ni posmoderno (en el sentido de Lyotard) y consiste, antes bien, en una crítica moderna de la modernidad (capitalista e industrial), inspirada en referencias culturales e históricas precapitalistas [17].
}

Para el alemán, esas referencias precapitalistas remitían a la mística judía, los mitos, la artesanía, la oralidad, la magia (en términos de Marcel Mauss); para el peruano estaban en el pasado comunitario inca y en el ámbito excéntrico latinoamericano que no acepta copias ni calcas eurocentristas. En el ejercicio de esa crítica moderna de la modernidad, ambos apuntan a la recuperación del ideal de la sociedad sin clases marxista. Manuel Reyes Mate ha destacado para el caso de Benjamin que dicha recuperación, por demás heterodoxa y distante de las pretensiones científicas del marxismo, lleva implícita la afirmación de que la política secularizada no genera valores, más bien ella retoma en determinadas circunstancias los ya existentes en la sociedad. Mariátegui más bien establece en su discurso una concepción de la política a la altura de la religión: “Pero el caso es que la política, para los que la sentimos elevada a la categoría de una religión, como dice Unamuno, es la trama misma de la historia" [2012a: 150]. 


\section{La sofisticación estético-política del intelectual vanguardista}

Lo que ahí yace reducido a escombros, el fragmento altamente significativo, el mero trozo, es la materia más noble de la creación barroca.

Walter Benjamin (El origen del 'trauerspiel' alemán)

Gran parte de la producción de estos dos ensayistas estuvo dedicada a reflexionar acerca del arte y la literatura. Escribieron poesía juvenil y escritura "creativa"; con mayor vigor Mariátegui, quien en 1923, cuando regresó a Perú luego de su estancia europea formativa en el marxismo y el internacionalismo, en dramática señal de ruptura definitiva con aquella etapa dandista, destruyó buena parte de sus poemas, cuentos y obras de teatro ${ }^{4}$. Ésta se convirtió así en la parte de la obra mariateguiana que más demoró en ser rescatada por editores y estudiosos.

Coinciden en haber desarrollado, como parte de su proceso de perfeccionamiento intelectual, una escritura ensayística fragmentaria e intertextual muy abierta al mosaico de citas configurado para producir nuevos sentidos. La ensayística de Benjamin transitó de los primeros intentos más formales y académicos a una versión enriquecida, autoconsciente y filosófica del flaneurismo proveniente de Baudelaire, uno de sus más grandes modelos intelectuales. Como el poeta y ensayista francés, se mantuvo atento al cambio de sensorio nacido en la modernidad con la tecnificación de la vida que significó el surgimiento de las grandes ciudades europeas industrializadas (en especial París). Muestra inacabada de ese proceso escritural es el monumental conjunto de citas y anotaciones titulado Libro de los pasajes, publicado póstumamente para ser objeto de incontables conjeturas. Con ese estudio centrado en París, Benjamin intentaba plantear vías de acceso por igual a la filosofía, la historia material y la historia de las ideas del siglo XIX.

En cambio, la escritura de Mariátegui fue de su juvenil crónica, antes practicada por los modernistas, al ensayo breve divulgado en publicaciones periódicas, esgrimido siempre como parte de su gran proyecto político-intelectual renovador del pensamiento peruano e hispanoamericano. Gran ejemplo de esa labor integral son sus Siete ensayos de interpretación de la realidad peruana

\footnotetext{
4 "Al igual que Valdelomar, Juan Croniqueur ensayó diversos géneros literarios: hizo poesía y dejó sin publicar un poemario que se titularía Tristeza y tal vez otro destinado a llamarse Sinfonía de la vida metropolitana; escribió alrededor de 13 cuentos, la mayoría de los cuales tuvieron como escenario el hipódromo; dos obras de teatro [...] [Flores Galindo 1980a: 83]".
} 
(1928), el primer gran análisis socioeconómico y cultural emprendido en Latinoamérica, que apareció antes esbozado en sus artículos periodísticos.

Estos ensayistas cifran en esa condición fragmentaria la efectividad e iluminaciones de su prosa. Por ende, en ambos casos, la lectura de sus obras significa reconstruir sus proyectos intelectuales: la fragmentación de sus escrituras no obsta para reconocer la profunda coherencia de ideas, manifiesta en una especie de macroensayo expuesto en brevedades que sólo en la lectura profunda y amorosa revela sus conexiones.

\section{Romanticismo de izquierda y marxismo heterodoxo}

La normalización sería la vuelta a la vida tranquila, el desahucio o

el sepelio de todo romanticismo, de todo heroísmo, de todo quijotismo de derecha y de izquierda. Nada de regresar, con los fascistas, al Medio Evo. Nada de avanzar: con los bolcheviques, hacia la Utopía. José Carlos Mariátegui ("Dos concepciones de la vida")

En aquellos tiempos revolucionarios de entreguerras, Mariátegui distinguió en el romanticismo una de las fuentes recurrentes de la cultura moderna, dos versiones confrontadas, dos vías rechazadas en su momento por la burguesía que poco antes había buscado refugio en la violencia fascista. El suyo fue el romanticismo, vanguardismo, heroísmo o quijotismo, diría Unamuno, de izquierda. Si bien ambos Ilegaron por caminos distintos a su etapa marxista-materialista, son conocidos por su insumisión y heterodoxia en todos los registros que practicaron: no militaron directamente en movimientos artísticos de vanguardia (aunque el indigenismo de Mariátegui sería lo más cercano a ello) ni asumieron acríticos los lineamientos irradiados por la Komintern.

Por un lado, luego de su etapa de frívolo dandismo, que incluyó su anexión al grupo de la revista Colónida (1916) comandada por Abraham Valdelomar (1888-1919), en su viaje a Europa entre 1919 y 1923, el Amauta estudió a Marx, aunque sólo algunas de sus obras habían sido traducidas a las lenguas que manejó ${ }^{5}$. No pudo viajar a la URSS porque se lo impidieron sus responsabilidades de

\footnotetext{
${ }^{5}$ Por ejemplo, La ideología alemana (1845-46), escrita con Engels, fue publicada completa hasta 1932. Según el testimonio de Anna Chiappe, una versión francesa de El capital y documentos acerca de la Revolución rusa en italiano formaron parte de su biblioteca en su estancia europea.
} 
padre y esposo. Además de Unamuno y González Prada, entre los grandes referentes para su perfil político-intelectual estuvieron Luis Araquistáin y su revista España (1915-1923), Henri Barbusse y el grupo de la revista Clarté (fundada en 1919) y, en Italia, quien terminó de alguna manera apadrinando su matrimonio con Anna Chiappe (1898-1990), Benedetto Croce (1866-1952), liberal y filósofo muy respetado en su país, marxista en su juventud (Materialismo histórico y economía marxista (1900). Y, por supuesto, Georges Sorel (1847-1922), uno de los autores clave en la construcción de su perspectiva marxista heterodoxa.

El filósofo francés, ideólogo del sindicalismo y de la huelga revolucionaria, es considerado por Mariátegui como un modernizador del marxismo en una nota autobiográfica preparada para el Congreso Constituyente de la Confederación Sindical Latinoamericana de Montevideo (mayo, 1929) y la Primera Conferencia Comunista Latinoamericana de Buenos Aires (junio, 1929):

\footnotetext{
Los Siete ensayos no son sino la aplicación de un método marxista, para los ortodoxos del marxismo insuficientemente rígido en cuanto reconoce singular importancia al aporte soreliano, pero que en concepto del autor corresponde al verdadero moderno marxismo, que no puede dejar de basarse en ninguna de las grandes adquisiciones de 1900 en filosofía, psicología y otros [2006b: 17].
}

Por otro lado, Benjamin llegó al comunismo de la mano de su enamorada, la actriz y directora teatral letona Asja Lacis (1891-1979), a quien conoció en Capri en 1924 y siguió hasta Moscú a finales de 1926 y principios de 1927. En esa estancia de un par de meses, consignada en su Diario de Moscú, decidió no incorporarse al Partido Comunista y, aun sin hablar ruso, registró las contradicciones del experimento político social en la URSS: a pesar de que en teoría se habían abolido las clases, al interior del partido se formaba un nuevo sistema de castas. Más que asimilar en toda su extensión la obra de Marx, estudió El dieciocho brumario de Luis Bonaparte (1852), además de Historia y conciencia de clase (1923) del húngaro Georg Lukacs y las Reflexiones sobre la violencia (1908) de Sorel. Esta última retomada en su ensayo de 1927 sobre el origen violento del derecho: "Para una crítica de la violencia". Así cita Benjamin a Sorel en ese ensayo:

Sorel se hace eco de ocasionales afirmaciones de Marx cuando reniega de todo tipo de programas, utopías, en una palabra, de fundaciones de derecho, al decir: "Con la huelga general desaparecen todas esas cosas bonitas; la revolución se manifiesta en forma de una revuelta clara y simple. Es un 
lugar que no está reservado ni para los sociólogos, ni para elegantes aficionados de la reforma social, ni para intelectuales para quienes pensar por el proletariado les sirve de profesión" [37].

En buena medida la insumisión, la heterodoxia, el anticientificismo, la crítica al progreso ("dogma del progreso" lo llamó Sorel) que desacredita también la teleología del marxismo, proviene en ambos pensadores de su filiación soreliana. Para muestra, un par de pronunciamientos en contra de la idea de progreso.

En la "Tesis IX" de Sobre el concepto de la historia, uno de los textos filosófico-políticos más reveladores y estudiados del siglo XX, Benjamin hace una aguda, poética y alegórica postulación antiprogreso:

\footnotetext{
Hay un cuadro de Klee que se Ilama Angelus Novus. En él está representado un ángel que parece como si estuviese a punto de alejarse de algo que mira atónitamente. Sus ojos están desmesuradamente abiertos, abierta su boca, las alas tendidas. El ángel de la historia ha de tener ese aspecto. Tiene el rostro vuelto hacia el pasado. En lo que a nosotros nos aparece como una cadena de acontecimientos, él ve una sola catástrofe, que incesantemente apila ruina sobre ruina y se las arroja a sus pies. Bien quisiera demorarse, despertar a los muertos y volver a juntar lo destrozado. Pero una tempestad sopla desde el paraíso, que se ha enredado en sus alas y es tan fuerte que el ángel ya no puede plegarlas. Esta tempestad lo arrastra irresistiblemente hacia el futuro, al que vuelve las espaldas, mientras el cúmulo de ruinas crece ante él hasta el cielo. Esta tempestad es lo que llamamos progreso [44].
}

Por su parte, Mariátegui en "Dos concepciones de la vida", siguiendo a Sorel afirmaba:

\footnotetext{
Bolcheviques y fascistas no se parecían a los revolucionarios y conservadores pre-bélicos. Carecían de la antigua superstición del progreso. Eran testigos, conscientes o inconscientes, de que la guerra había demostrado a la humanidad que aún podían sobrevenir hechos superiores a la previsión de la Ciencia y también hechos contrarios al interés de la Civilización [32].
}

En este mismo sentido crítico, mientras el alemán no recurre al proletario sino al lumpen, el trapero, el anciano, la prostituta, los improductivos excluidos desde el punto de vista marxista, otra manera de resistir frente a la lógica moderna; el peruano centra su reflexión en otros excluidos radicales de la modernidad, no se diga del marxismo (además de las mujeres, sobre las que también escribió): los latinoamericanos todos y en especial los indios, campesinos en condiciones de servidumbre. 


\section{La seducción vanguardista}

Desde mi punto de vista nada más característico del perfil de estos intelectuales "románticos de izquierda" que sentirse seducidos, encantados, por la radical proclamación de libertad vanguardista del surrealismo y, al mismo tiempo, manifestarse independientes del movimiento. En esto coinciden Mariátegui y Benjamin, aunque en su cercanía con el grupo francés sólo el alemán definió como peligroso su acercamiento a la tendencia liderada por André Breton.

Como intérprete y crítico del vanguardismo, Mariátegui precedió a Benjamin. Antes incluso de su regreso de Europa, donde más bien se dedicó a seguir el debate político europeo ${ }^{6}$, el ensayista dio muestra de la sofisticación de sus concepciones estético-políticas. En "Aspectos viejos y nuevos del futurismo" $(1921)^{7}$, artículo vital para su reflexión estética, reseña la reaparición pública en la posguerra de Filippo Tommaso Marinetti (1876-1944), fundador del movimiento pionero de vanguardia surgido en Italia en 1909. Entre los apuntes acerca del contexto que primaba en ese retorno futurista, Mariátegui destaca el surgimiento de la pluralidad de movimientos de vanguardia (cubismo, expresionismo, dadaísmo) y la paulatina aceptación de aquellas obras rupturistas en los circuitos del mercado del arte. Sobre todo, Ilama la atención del comentarista lo que consideró "una de las desviaciones del movimiento": la instauración de un programa político futurista.

En este ensayo Mariátegui se alejó del frívolo culto a la personalidad, su crítica se ensanchó hasta situar la obra y los discursos artísticos en su contexto sociopolítico. No expuso entonces la incompatibilidad de la estética y la política: "El grande artista no fue nunca apolítico. No fue apolítico el Dante. No lo fue Byron. No lo fue Víctor Hugo. No lo es Bernard Shaw. No lo es Anatole France. No lo es Romain Rolland. No lo es Gabriel D’Annunzio. No lo es Máximo Gorki" [2006a: 37]. Más bien evidenció, como lo haría años después Walter Benjamin, la falaz sustitución de la política por la estética llevada a cabo en aquel cónclave vanguardista:

\footnotetext{
No hay, pues, nada que reprochar a Marinetti por haber pensado que el artista debía tener un ideal político. Pero sí hay que reírse de él por haber supuesto que un comité de artistas podía improvisar de sobremesa una doctrina política. La ideología política de un artista no puede salir de las asambleas de estetas. Tiene que ser una ideología plena de vida, de emoción, de humanidad y de verdad. No una concepción artificial, literaria y falsa [37].
}

\footnotetext{
${ }^{6}$ El volumen Cartas de Italia contiene sólo 9 artículos, de 46 que lo conforman, dedicados a cuestiones estéticas.

${ }^{7}$ Publicado en El Tiempo, 3 de agosto de 1921.

8 "La obra de arte en la época de su reproductibilidad técnica" (1936, primera redacción).
} 
Unos quince años después, en "La obra de arte en la época de su reproductibilidad técnica" (1936, primera redacción), un ensayo que aborda el complejo cambio de sensorio proveniente de la tecnificación moderna y sobre todo de la reproducción técnica de las imágenes a través de la fotografía y el cine, Benjamin ensanchó la reflexión acerca de la estetización fascista de la política como una tendencia contemporánea europea que se repetía en distintos países hasta llegar a la Alemania nacionalsocialista:

\footnotetext{
Las masas sin duda tienen el derecho a un cambio en la relación de propiedad, pero el fascismo trata de otorgarles una expresión, para conservarla. Así, en consecuencia, desemboca en la estetización de la política. Ya con D’Annunzio, la decadencia hizo su entrada en la política, con Marinetti lo hizo el futurismo y al fin con Hitler la tradición de Schwabing [45].
}

Otra coincidencia, el Amauta, antes admirador de Gabriele D'Annunzio (1863-1938), primero como poeta después como militar y político, criticó también el aristocratismo artificioso con que el italiano había marcado su experiencia juvenil de dandismo literario.

\section{Contra el artepurismo}

Tanto en la obra del peruano como en la del alemán son reiteradas las argumentaciones en contra de las trasnochadas actitudes artepuristas de sus contemporáneos, herederas de aquel romanticismo que reaccionó en contra del advenimiento del modo de producción capitalista. La modernidad transformó el papel de los artistas, antes protegidos del mecenazgo noble, en productores insertos en la lógica y canales del mercado. El gran ensayo acerca del tema en el caso de Mariátegui es "La torre de marfil" (1924)9 , en el que retomó aquella reflexión para definir la que fue en adelante su más firme posición en contra de la figura del creador individualista y apolítico. Con una prosa creativa que reflexiona mediante analogías y metáforas, en su ensayo retoma, sin mencionarlo, una apreciación tradicionalmente atribuida al crítico francés Charles Augustin de Sainte-Beuve (18041869), quien caracterizó la costumbre solitaria del poeta romántico Alfred de Vigny (1797-1863) como una reclusión en su torre de marfil, acuñando así una de las etiquetas típicas de las tendencias artepuristas a partir del romanticismo.

\footnotetext{
${ }^{9}$ Publicado en Mundial, 7 de noviembre de 1924.
} 
En este mismo artículo ejerce una idea dialéctica, presente en ensayos previos (como "Postimpresionismo y cubismo", publicado en enero de 1924), de la historia cultural dinamizada por la oposición entre una época clásica y otra romántica.

\footnotetext{
El torremarfilismo formó parte de esa reacción romántica de muchos artistas del siglo pasado contra la democracia capitalista y burguesa. Los artistas se veían tratados desdeñosamente por el capital y la burguesía. Se apoderaba, por ende, de sus espíritus una imprecisa nostalgia de los tiempos pretéritos. Recordaban que bajo la aristocracia y la Iglesia, su suerte había sido mejor. El materialismo de una civilización que cotizaba una obra de arte como mercadería los irritaba. Les parecía horrible que la obra de arte necesitase réclame, empresarios, etc., ni más ni menos que una manufactura, para conseguir precio, comprador y mercado. A este estado de ánimo corresponde una literatura saturada de rencor y de desprecio contra la burguesía. Los burgueses eran atacados no como ahora, desde puntos de vista revolucionarios, sino desde puntos de vista reaccionarios [73].
}

Mariátegui busca el origen de la metafórica torre producida por el decadentismo de entre siglos hasta situarla históricamente ("Tiempos quietos, normales, burocráticos, pudieron tolerarla"), como tipo concreto de edificio arquitectónico producido sobre todo en las sociedades del Medievo. En este sentido, el pensamiento de Mariátegui opera por un materialismo muy creativo. Uno de sus recursos reflexivos era la construcción de una imagen ilustrativa de la abstracción sobre la que versaran sus argumentos. En un ensayo sobre Rainer Maria Rilke, anota: “todas las teorías modernas se caracterizan por la posibilidad de poder expresarse gráficamente" [2012b: 43-44].

Los ensayistas concuerdan en el recurso de la historia del urbanismo y de las dinámicas citadinas como concreción del mundo de las ideas vigentes en las distintas épocas. El Benjamin de Libro de los pasajes, que abre con "París, capital del siglo XIX"; el de Baudelaire. Un poeta en el esplendor del capitalismo piensa por igual sobre la modernidad, el arte y la poesía a través de la ciudad, sus espacios y personajes prototípicos.

Y, como lo describió Walter Benjamin, en "El autor como productor"10, una década después de aquel ensayo del Amauta, el capitalismo le echó en cara al artista romántico y artepurista su nueva condición desauratizada. Aquellos movimientos regresivos, romanticismo y decadentismo, tomaron el símbolo aislacionista para significar el rechazo al cambio radical del modo de producción y del racionalismo ilustrado. En su argumentación enfatizó la obligada superación de aquel arte ritual y artistas auratizados previos a la modernidad, para dejar su lugar al arte revolucionario, el autor

10 "El autor como productor" (1934), discurso leído por el alemán en el Instituto de Estudios del Fascismo de París, forma parte de la etapa de más intenso marxismo y materialismo en la trayectoria de Benjamin. 
politizado, artista de tendencia que, consciente de su papel y responsabilidades sociales, renuncia a aquella pretendida autonomía, no sólo como sujeto ideológico sino como productor, participante del engranaje económico social. Producto de una etapa optimista del alemán sobre el destino de la Revolución rusa y el comunismo, en el dramaturgo Sergei Tretiakov (1892-1937) identificó el modelo de escritor "operante" de tendencia política correcta y técnica literaria progresiva. Tretiakov fue condenado a muerte (1937) acusado de espionaje por las autoridades soviéticas que se habían mostrado intolerantes a sus manifestaciones ideológicas y artísticas. Aquel optimismo de Benjamin se desvaneció por completo a raíz del pacto Hitler-Stalin (1939-1941). De hecho, Scholem consideró las tesis Sobre el concepto de la historia como una reacción del autor a dicho pacto.

\section{El surrealismo, la vanguardia politizada}

Tanto Mariátegui como Benjamin hallaron, en contraste, una congruente politización de la vanguardia artística en la adhesión al Partido Comunista de los surrealistas franceses encabezados por André Breton (1896-1966). Con su antecedente en el dadaísmo, surgido en 1916 a iniciativa del poeta alemán Hugo Ball (1886-1927) en su Cabaret Voltaire de Zurich, Suiza, y continuado por el rumano Tristan Tzara (1896-1963); los surrealistas heredaron una inusitada libertad nihilista en el lenguaje poético, en especial Breton y Louis Aragon (1897-1982), quienes participaron desde Francia en la fase dadaísta internacional ${ }^{11}$. El aspecto moral y político resultó a fin de cuentas la nota diferenciadora con el nihilismo dadaísta.

Para ambos, el surrealismo (Mariátegui lo llamó suprarrealismo) identificó no sólo el particular movimiento que incluyó "los mejores espíritus" franceses sino toda "una vía de la literatura mundial", una experiencia estética moderna cada vez más emancipadora. La propuesta de Breton, crítica del mito del progreso y del exceso racionalista en el "Primer manifiesto" (1924), esa específica renovación del arte y de la sociedad mediante el contacto con los procesos ocultos de la mente estudiados por Freud.

A diferencia de Walter Benjamin ${ }^{12}$, quien emparentó con el surrealismo algún antepasado imprevisto (Dostoyevski), Mariátegui agrupó en el plano internacional a quienes, según él, transitaban esa ruta contemporánea de las letras y el arte en occidente:

\footnotetext{
${ }^{11}$ Si bien la revista Littérature (33 números, de 1919 a 1924), considerada la primera publicación surrealista, dedicó parte de sus páginas a Dadá, no se redujo al nihilismo y desde entonces mostró las preocupaciones morales que después caracterizaron al surrealismo.

12 "El surrealismo. La última instantánea de la inteligencia europea" (1929). En el "Primer manifiesto", Bretón no menciona como surrealista a Dostoyevski, aunque sí lo hace con muchos antecesores: Sade, Rimbaud, Swift, Poe, Chateaubriand, Baudelaire, Mallarmé, Jarry, Saint-Pol-Roux, Reverdy, Saint-John Perse, Lautréamont, etcétera.
} 


\begin{abstract}
Suprarrealista es el italiano Pirandello. Suprarrealista es el norteamericano Waldo Frank, suprarrealista es el rumano Boris Pilniak. Nada importa que trabajen fuera y lejos del manípulo suprarrealista que acaudillan, en París, Aragón, Breton, Éluard y Soupault [2006c: 93-94].
\end{abstract}

En el ensayo de 1926 del que proviene la cita, "La realidad y la ficción"13, Mariátegui ya se había interesado en el movimiento surrealista que había irrumpido en el panorama europeo dos años antes. Ahí mismo se manifestó en contra del limitado realismo exteriorista del pasado y, en estos despejes, se entiende mejor cuán lejos se encontraba el Amauta del dogmatismo que caracterizó años después al realismo socialista del estalinismo:

\footnotetext{
El realismo nos alejaba en la literatura de la realidad. La experiencia realista no nos ha servido sino para demostrarnos que sólo podemos encontrar la realidad por los caminos de la fantasía. Y esto ha producido el suprarrealismo que no es sólo una escuela o un movimiento de la literatura francesa sino una tendencia, una vía de la literatura mundial [2006c: 93].
}

El Amauta se mantuvo muy atento a las propuestas y reacciones que el movimiento surrealista generó en la segunda mitad de los años veinte. La adhesión de Breton, Éluard, Aragon, Peret y Unik al Partido Comunista en 1927 incentivó aún más el interés del peruano ${ }^{14}$.

En cambio, como parte de su amplio proyecto crítico dirigido a explorar la cultura moderna, Benjamin se ocupó en ensayos agudos de las propuestas literarias y artísticas de escritores modernos: Baudelaire, Hebel, Kafka, Valéry, Proust, Leskov, etcétera. Se detuvo en el surrealismo como movimiento hasta 1929, cuando publicó "El surrealismo. La última instantánea de la inteligencia europea". La hipótesis de Michael Löwy sobre el contacto y la fascinación del ensayista con el movimiento encabezado por Breton apunta también a 1926-1927, cuando el alemán pasó dos veranos en París. Así, en una carta a Theodor Adorno (1903-1969), Benjamin ubicaba el origen de su proyecto de Libro de los pasajes en la gran impresión que le causó la novela El campesino de París (Le paysan de Paris de 1926) de Louis Aragon (1897-1982) ${ }^{15}$.

Löwy comenta también ese juicio popularizado e inexacto, debido a Ernst Bloch (1885-1977), por el que se consideró surrealista la prosa de Benjamin en Calle de dirección única (1928). Aunque no niega que en ese libro de prosas breves reveladoras hay de hecho huellas de aquella proximidad que, en una carta a Scholem, el autor adivinó "fatal" para él. Sin embargo, el propio texto sobre el

\footnotetext{
${ }^{13}$ Publicado en Perricholi (Lima, 25 de marzo de 1926).

${ }^{14}$ Hay que recordar que el líder de los surrealistas había declarado en Légitime défense (1926): "He juzgado inútil hacerme inscribir en el Partido Comunista".

${ }^{15}$ Carta del 31 de mayo de 1935.
} 
surrealismo, descrito por Löwy como "ensayo poético, filosófico y político de una gran importancia, recorrido por intuiciones fulgurantes e 'iluminaciones profanas' sorprendentes", podría pensarse a la vez como constructor de esa distancia crítica y como una apropiación sutil del sentido emancipador e iconoclasta de la experiencia artístico-política del grupo encabezado por Breton.

Destaca en la argumentación benjaminiana el ejercicio de esa organización del pesimismo a la que conminó Pierre Naville en La revolución y los intelectuales (1926). Esa clave política del movimiento surrealista aunada a la fuerza de la ebriedad, cuya manifestación superior es la iluminación profana, materialista, ebriedad que guio a Benjamin para atisbar la catástrofe que sobrevendría años después mediante la segunda guerra y la tecnificación de la muerte que significó el holocausto:

\footnotetext{
Desconfianza en el destino de la literatura, desconfianza en el destino de la libertad, desconfianza en el destino de la humanidad europea, pero sobre todo desconfianza, desconfianza y desconfianza en todo entendimiento: entre las clases, pueblos, individuos. Y sólo una confianza ilimitada en la I. G. Farben y en la pacífica modernización de la Luftwaffe [315].
}

Löwy enfatiza que, en esta última irónica confianza, el escritor prevé la destrucción que ocurrirá años después en Europa por la acción de la Fuerza Aérea alemana (Luftwaffe) y, más sorprendente aún, Benjamin acierta en mencionar a la empresa farmacéutica (I. G. Farben) fabricante del pesticida Zyklon B, utilizado en el exterminio de personas en las cámaras de gas.

Si para Benjamin el aspecto central del surrealismo politizado pretendía "ganar las fuerzas de la embriaguez para el servicio de la revolución" (2007 313), para el Amauta el disparate de la experimentación artística y la actuación política de los suprarrealistas, a diferencia de los futuristas italianos, habrían sido debidamente desconectadas por el grupo al adherirse al comunismo:

\footnotetext{
Los suprarrealistas no ejercen su derecho al disparate, al subjetivismo absoluto, sino en el arte; en todo lo demás, se comportan cuerdamente y esta es otra de las cosas que los diferencian de las precedentes, escandalosas variedades, revolucionarias o románticas, de la historia de la literatura. Pero nada rehúsan tanto los suprarrealistas como confinarse voluntariamente en la pura especulación artística. Autonomía del arte, sí; pero, no clausura del arte [1991: 393].
} 
En este ensayo, "Balance del suprarrealismo" $(1930)^{16}$, uno de sus últimos textos, el pensador peruano comentó "El segundo manifiesto" de Breton, aparecido en el último número de La Révolution Surréaliste (número XII, diciembre de 1930), y repasó la trayectoria del movimiento con el que, a fin de cuentas, luego de fallecido Mariátegui, cerró la experimentación vanguardista histórica europea. Para el Amauta, en ese panorama de corrientes artísticas y literarias, sólo el suprarrealismo, armado de su participación y experiencia política revolucionaria, había trascendido en su propuesta a aquellos otros experimentos subversivos.

No he terminado con la exploración de concordancias entre Mariátegui y Benjamin. Fueron lectores críticos de Bergson y de Freud: Mariátegui en "El freudismo en la literatura contemporánea" (1926), Benjamin en "El surrealismo..." o en "Sobre algunos tópicos en Baudelaire" (1939); descifradores del vanguardismo en el cine de Chaplin: el alemán en "Chaplin, una mirada retrospectiva" (1929) o en "La obra de arte...", el peruano en "Esquema de una explicación de Chaplin" (1928). Sólo por mencionar algunos de los cabos sueltos.

\section{Trayectorias paralelas}

Como resulta obvio en la consignación de las fechas de publicación y en los órganos que reprodujeron sus ensayos, Mariátegui, quien vivió unos doce años menos, le antecedió en varios de sus intereses e ideas a un Benjamin que además era mayor que el peruano por un par de años. Es evidente que las ideas del Amauta, en un circuito de mayores alcances como el europeo, habrían tenido una repercusión internacional mucho mayor que la obtenida en aquel tiempo. El impacto en el diálogo intelectual es de hecho un problema de canales y de mediaciones.

Quiero cerrar este artículo mencionando un par de discrepancias mayores en la producción intelectual de estos autores: su posesión o carencia de un proyecto colectivo y el grado de profundidad de sus concepciones del lenguaje.

La primera de esas discrepancias es clara: Benjamin no tuvo en su ejercicio intelectual nada parecido a la revista Amauta (1926-1930). Mariátegui, como auténtico pionero, sentó las bases de una colectividad intelectual dedicada a pensar en su complejidad sociocultural en y desde el Perú e Hispanoamérica.

\footnotetext{
${ }^{16}$ Publicado en dos partes en Variedades: Lima, 19 de febrero y 5 de marzo de 1930.
} 
Por otro lado, Benjamin, apoyado en la formación académica de la que careció el Amauta, diseñó una teoría del lenguaje que en buena medida fundamenta toda su obra ensayística. Expuesta en el breve ensayo "Sobre el lenguaje en cuanto tal y sobre el lenguaje del hombre" (1916), la juvenil teoría benjaminiana del lenguaje, aunque sincronizada plenamente con esa primera etapa de su labor dominada por preocupaciones teológicas, es en muchos sentidos modelo y punto de partida para el desarrollo posterior de varias vías por las que transita su reflexión. Si pensamos en sus indagaciones de crítica literaria o las vinculadas con la indagación del lenguaje, hay ejemplos directamente derivados de su ensayo escrito en 1916. Así ocurre con los producidos algunos años después, como "La tarea del traductor" (1923), o con sus obras de madurez, como "El narrador" de 1936. Pero no sólo estos registros que bordean la filosofía del lenguaje tienen su raíz en el ensayo "Sobre el lenguaje", también se encuentran anunciados en dicho artículo los primeros visos de sus reflexiones sobre el origen del derecho incluidas en "Para una crítica de la violencia" (1927). Hasta aquí el apunte de esa divergencia que en el alemán sirve para explorar aspectos en los que Mariátegui no indagó con tales herramientas e interés. Para mayores detalles de este deslinde remito a un texto de próxima publicación en que me ocupo de explorar las concepciones del lenguaje en la obra de Benjamin. 


\section{BIBLIOGRAFÍA}

BENJAMIN, Walter: Diario de Moscú. Buenos Aires: Ediciones Godot, 2015.

: El narrador. Traducción de Pablo Oyarzún. Santiago de Chile: Metales Pesados, 2008.

:: «El surrealismo. La última instantánea de la inteligencia europea», en Obras. Libro II. Vol.

1. Edición de Rolf Tiedemann y Hermann Schweppenhäuser. Madrid: Abada, 2007, pp. 301-316.

— : «La obra de arte en la época de su reproductibilidad técnica» (Primera redacción), en Obras. Libro I. Vol. 2. Edición de Rolf Tiedemann y Hermann Schweppenhäuser. Madrid: Abada, 2008. pp.11-47.

—_: «La tarea del traductor», en Dámaso López García (ed.), Teorías de la traducción. Antología de textos. Traducción de Hans Christian Hagedorn. Cuenca: Universidad de Castilla La Mancha, 1996, pp. 335-347.

_- «Para una crítica de la violencia», en Para una crítica de la violencia y otros ensayos. Iluminaciones IV. Tercera edición. Traducción de Roberto J. Blatt Weinstein. Madrid: Taurus, 2001. pp. 23-45.

— : «Sobre el concepto de historia», en La dialéctica en suspenso. Fragmentos sobre historia. Segunda edición. Traducción de Pablo Oyarzún Robles. Santiago: LOM / Arcis, 2009, pp. 37-53.

: «Sobre el lenguaje en cuanto tal y sobre el lenguaje del hombre», en Obras. Libro II. Vol.

1. Edición de Rolf Tiedemann y Hermann Schweppenhäuser. Madrid: Abada, 2007, pp. 144-162.

CASETTA, Giovanni: «Mariátegui: México y su revolución», Anuario Mariateguiano Vol. VI, No. 6, Lima, Amauta, 1994, pp. 104-124.

FLORES GALINDO, Alberto: «Juan Croniqueur. 1914/1918», Revista Apuntes. Número 10, 1980a, pp. 81-98.

: La agonía de Mariátegui. La polémica con la Kominterm. Lima: Centro de Estudios y Promoción del Desarrollo, 1980b.

LÖWY, Michael. «Mística revolucionaria: José Carlos Mariátegui y la religión», Utopía y praxis latinoamericana. Volumen 10, número 28. Enero-marzo de 2005, pp. 49-59.

: Walter Benjamin: aviso de incendio. Una lectura de las tesis "Sobre el concepto de la historia". Segunda edición. Buenos Aires: Fondo de Cultura Económica, 2012. 
MARIÁTEGUI, José Carlos: «Arte, revolución y decadencia», en Ensayos literarios. Sobre Joyce, Breton y las vanguardias europeas. Buenos Aires: Mardulce, 2012a, pp. 147-151.

— : "Aspectos viejos y nuevos del futurismo», en Literatura y estética. Selección de Mirla Alcibíades. Caracas: Biblioteca Ayacucho, 2006a, pp. 35-38.

— : «Del autor", en Ideología y política. Caracas: Ministerio de Comunicación e Información, 2006b, pp. 17-19.

_- «Dos concepciones de la vida», en El alma matinal y otras estaciones del hombre de hoy. Rosario: Ediciones del Sertão, 2014, pp. 29-34.

——: «El balance del suprarrealismo», en Textos básicos. Selección de Aníbal Quijano. México: Fondo de Cultura Económica, 1991, pp. 392-396.

——: «El grupo suprarrealista y Clarté», en Ensayos literarios. Sobre Joyce, Breton y las vanguardias europeas. Buenos Aires: Mardulce, 2012b, pp. 79-83.

— : «La realidad y la ficción», en Literatura y estética. Selección de Mirla Alcibíades. Caracas: Biblioteca Ayacucho, 2006c, pp. 92-95. 